\title{
Group B Streptococcus Screening
}

National Cancer Institute

\section{Source}

National Cancer Institute. Group B Streptococcus Screening. NCI Thesaurus. Code C92805.

Screening with a swab from the vaginal and rectal areas in late pregnancy to test for the presence of Group B streptococcal infection. 